theoretical ideas is that it should be possible to distinguish between excited and ionized atoms in the solid by tests on photo-conduction and on phosphorescence. In the simplest cases the phosphors with a hyperbolic decay law should be photo-conducting, while those with exponential decay laws should not. The well-known high efficiency of alpha-particle excitation of luminescence in zinc sulphide phosphors, it was pointed out, is not due to the absorption of energy by the whole lattice and its subsequent transfer to the activating impurity atoms, but to the production of numbers of fairly high-energy electrons ( $\delta$-rays) colliding directly with the impurities.

The last part of the meeting was occupied with chemiluminescence, which is usually concerned with the production of light during chemical reactions ; more recently, it has been shown that some reactions produce feeble radiations in the far ultra-violet. Bioluminescence is now generally regarded as a chemiluminescence in which the luciferin is oxidized in the presence of molecular oxygen and the enzyme luciferase. The work of Polanyi and Evans on sodium and chlorine vapour reactions is typical of one type of chemiluminescence and indicates that the production of light is a consequence of the following steps :

$$
\begin{aligned}
& \mathrm{Na}+X_{2}=\mathrm{Na} X+X, \\
& X+\mathrm{Na}_{2}=\mathrm{Na} X^{*}+\mathrm{Na}, \\
& \mathrm{Na} X^{*}+\mathrm{Na}=\mathrm{Na} X+\mathrm{Na}+h \nu,
\end{aligned}
$$

where $X$ is $\mathrm{Cl}, \mathrm{Br}$ or $\mathrm{I}$, rather than one involving a neutral halide molecule and an excited sodium atom. Bawn has recently extended this type of work to reactions involving organic halides such as $\mathrm{CH}_{2} \mathrm{Cl}_{2}, \mathrm{CH}_{3} \cdot \mathrm{CCl}_{2} \cdot \mathrm{CH}_{3}$, etc.

The other type of chemiluminescence to be discussed was the oxidation process appearing in the luciferin reaction already mentioned, the oxidation of the Grignard reagents, the dimethyldiacridylium salts, and many others. Two methods of approach were apparent at the discussions. Weiss adopted the more physical method, and discussed the cases where the chemiluminescence can be regarded as the reverse of photochemical dissociation $(A+B \rightleftharpoons A B+h v)$ and the quantum conditions associated with this type of reaction. Drew, on the other hand, has attacked the problem of chemiluminescence in the phthalic hydrazides from the purely chemical point of view of investigating the reactions that lead to their formation, the effects of the nature and position of substituents, and the interaction of the hydrazides with hydrogen peroxide.

The discussions as a whole were of value in making clear the precise nature of some of the important problems to be solved, and both the official meetings, and the more informal exchanges of views that inevitably take place on occasions of this kind, played their part.

J. T. RANDALL.

\title{
The State and Medical Research in Great Britain*
}

THE annual Harveian Oration was delivered by Sir Edward Mellanby, secretary of the Medical Research Council, on October 18 at the Royal College of Physicians, London, the subject of his discourse being "The State and Medical Research".

Sir Edward first paid a tribute to Harvey, who "stands out as one of the greatest investigators, and his work-a wonderful combination of observation and experiment-is an example of the finest achievement of the human mind". Harvey's election in 1630 as physician-in-ordinary to Charles I brought him into close association with the head of the State, and one result of this association was permission to make use of deer and other animals in the royal demesnes for studyprobably the first instance, with certain legendary exceptions, of State support for medical research. Harvey's example has induced more and more individuals to take up research, and the revolu-

- Substarce of the Harveian Oration before the Royal College of Physicians, delivered by Sir Edward Mellanby, K.C.B., F.R.S. on October 18. tionary changes in medicine during the past sixty years only increase the appreciation of his foresight and skill. These revolutionary changes include the introduction of new methods for the diagnosis, treatment and prevention of disease ; the enormous increase in hospital accommodation ; the formation and development of the clinical laboratory and radiological department; and the expansion and multiplication of the public health services.

Increase of knowledge has been mainly responsible for these developments, and it has come to be realized that health and disease are not conditions conferred upon man for his humble acceptance, but that by a certain method (Harvey's method) disease may be controlled and death itself warded off, and more and more men and women proceed to investigate and to accumulate knowledge.

The acceptance in Great Britain of the new urge for research has been comparatively recent. The late Earl Balfour said in 1896, "I have all my life 
been an ardent believer in a cause which is often laughed at-the cause of the endowment of research. I think there is no branch of knowledge in which it may find a more useful field of application than in that of advancing medical knowledge." Again, in 1900, Earl Balfour pointed out how meagre was the equipment for medical research in Great Britain compared with Germany, France, Switzerland and Italy. Medical research in these countries was undertaken for its own sake, and not necessarily for the elimination of disease, though the leaders of industry there and in the United States soon realized that it was to their advantage to devote some expenditure to the furtherance of research.

It has been said that Great Britain needed the stimulus of the Great War to realize the importance of research, resulting in the setting up of the Department of Scientific and Industrial Research in 1915. Actually, the Medical Research Committee came into being somewhat earlier, in 1913, under the National Health Insurance Joint Commission, to administer funds provided by the National Insurance Act of 1911. This arrangement terminated in 1919, and in 1920 the Medical Research Council took the place of the Committee, funds for the work of which were provided directly from the Treasury in the form of a Parliamentary grant-in-aid.

Sir Edward Mellanby then discussed the possible sources that might be anticipated for the endowment of research, medical or industrial. Had funds, private or otherwise, not been available, such men as Darwin, Newton, Humphry Davy and Faraday could scarcely have pursued their work and made their discoveries. On the other hand, it is true that some of the best work has been done by those labouring under conditions of extreme simplicity, notable instances being those of Claude Bernard and Louis Pasteur. Endowment of research, medical or industrial, by private individuals has been the exception in Great Britain, but the American record in this respect during the past twenty years has been a fine one, and the extensive support given to British medical research by the Rockefeller Foundation may prove a stimulus to private munificence here, of which the Nuffield scheme at Oxford is possibly an indication.

The ability to discover, Sir Edward remarked, is present in all grades of society; but the real discoverer is rare in all classes, and it should be the object of civilized communities to find him and to foster his activities. Failing adequate private endowment, all will agree that there is justification in Great Britain for State support for research. State support must, however, be associated with State control, a condition disagreeable to many owing to the fear of loss of freedom for the investigator. History, however, has clearly demonstrated that State endowment is compatible with the best type of medical research, and indeed Sir Edward stated that one of the main objects of his discourse was to show how State control of medical research can be associated with freedom to the investigator.

It is true that State control may have certain dangers, such as political influences, implicit in any State activity ; not only has political influence been absent, but even political interest has been uncommon in the affairs of the Medical Research Council. While Parliament possesses ultimate control, the Council has been given great latitude in its policy and finance, and the disposal of the funds supplied is at its complete disposal. Of the present eleven members of the Council, eight are chosen for their scientific and medical attainments, each one approved by both the Lord President of the Privy Council and the president of the Royal Society; political influence has had no detrimental effect upon the medical researches controlled by the Council. A safeguard against bias and dictatorship on the part of the Council is the fact that there is constant change of personnel, each individual term of office being limited to four years.

The appraisal of a new discovery is clearly difficult, and mistakes are inevitable from time to time; it is seldom in the facts of a discovery, but rather in their interpretation, that mistakes are made, and in the Council's work more mistakes are due to benevolence than to harshness.

After this statement of the case for State support of medical research, and vindication of its impartiality in Great Britain, Sir Edward pro. ceeded to describe the general principles guiding the actions, and the work, of the Medical Research Council. For general guidance of detailed work, the Council relies on the advice of special committees, of which there are twenty-seven at present, some being appointed conjointly with other bodies, for example with the Royal Society of Medicine (anæsthetics), the Lister Institute (vitamins), the British Empire Cancer Campaign (radiology) and others. The Industrial Health Research Board, a subsidiary of the Medical Research Council, also receives advice from committees dealing with its problems. The services of all members of these committees are given voluntarily. Sir Edward also paid a tribute to the willing co-operation of the Royal Colleges of Physicians and of Surgeons.

With regard to finance, the present annual income of the Council amounts to about $£ 220,000$, of which the State contributes $£ 195,000$, a sum 
that has recently been criticized as being meagre in view of the possibilities through research of the reduction of expenditure on the country's toll of sickness, which costs the Government between 200 and 300 million pounds annually. In addition, private funds held by the Council contribute $£ 13,000$ per annum, and a sum amounting to $£ 12,000$ is derived from grants made by certain bodies for special purposes, including the Rockefeller Foundation, the Leverhulme Trustees, the British Empire Cancer Campaign and others.

The principal factor limiting research activity is personnel, and one of the endeavours of the Council is to increase the number of research workers, but more funds will be necessary when more trained investigators become available. Some system is also required for financing sudden important calls for organized research when these arise.

The Council has also established and maintains the National Institute for Medical Research at Hampstead and Mill Hill, supports a growing number of research units, both clinical and laboratory, and provides grants for individual workers. At the National Institute for Medical Research, under the direction of Sir Henry Dale, work is done in two main divisions, one including researches coming under physiology, pharmacology, and biochemistry, the other those under experimental pathology and bacteriology. Here, in addition to research, the standardization of biological products, such as antitoxins, certain drugs, vitamins, and hormones, is undertaken, whereby the exact strengths of these products may be described in terms of units, and the doctor is thus able to prescribe known amounts of their active principles.

The Medical Research Council also maintains at the Lister Institute a National Collection of Type Cultures, so that any medical man in the world can obtain at nominal cost a culture of almost any known micro-organism. At the Pathological Laboratory of the University of Oxford a Standards Department is maintained, from which prepara- tions of bacterial suspensions and sera are supplied for use in the diagnosis of diseases, such as enteric and undulant fevers, and dysentery.

The placing of units of research in different institutions has developed with much success in recent years. The Council provides the salaries and the actual cost of the research, the institution furnishing the accommodation. There have thus been established the neurological research unit at the Hospital for Diseases of the Nervous System, Queen Square, London, the research department on puerperal infections at Queen Charlotte's Hospital, London, the clinical research department at University College Hospital, London, and others. Research grants to individuals are also made, such personal grants being usually limited to three years, and the worker is given full freedom to develop his problem. A third activity of the Council is the award of travelling fellowships in research, and a number of the younger medical men of Great Britain have been past holders of these fellowships. Assistance is also given to Government departments on problems of health and disease.

After some remarks regarding initiative in research, and a reply to criticisms respecting the type of medical research supported by the Council, Sir Edward Mellanby had something to say about the future, observing that the difficulty he foresaw was not that of obtaining knowledge, but of its application to human needs. He concluded his oration by pointing out that it is the function of the Medical Research Council to promote discovery, not to implement its application. $\mathrm{He}_{\mathrm{e}}$ made an appeal to the Royal College of Physicians of London, suggesting that the College as a body and through its fellows and members might use its prestige and influence in guiding the profession and the public to appropriate action, if such be needed, when scientific discovery has supplied new knowledge of importance to public health. Finally, he submitted that the entry of the State into the field of medical discovery has been both stimulating and fruitful.

\section{Obituary Notice}

Sir Basil Mott, Bart., C.B., F.R.S.

$\mathrm{B}^{\mathrm{x}}$ the death of Sir Basil Mott on September 7, a pioneer in engineering practice, the Royal Society loses one of the few engineers who have been admitted to its fellowship. He formed a link-one of the very few remaining-with those great figures whose names became almost household words in the latter part of the nineteenth century as the creators of outstanding engineering works-Benjamin Baker, Wolfe Barry, Charles Hawksley, Douglas Fox and others. When a young man he gained experience, as a mining engineer, in work underground, which was invaluable in the pioneering work involved in deep tunnelling with the Greathead shield, the use of which has revolutionized the solution of transport problems in crowded cities. The first use of this method on a large scale was in the construction of the 'City and Southwark Subway', which formed the first part of the 'City and South London Railway' and was taken in hand in October 1886. Basil 